\title{
Colchicine-Induced Myopathy with Normal Creatine Phosphokinase Level in a Renal Transplant Patient
}

\author{
Kayser Çağlara Mükerrem Safali ${ }^{b}$ Izzet Yavuza Zeki Odabaşic \\ Müjdat Yenicesua Abdülgaffar Vurala \\ Departments of a Nephrology, bPathology, and cNeurology, Gülhane Medical School, Ankara, Turkey
}

\section{Key Words}

Colchicine $\cdot$ Myopathy $\cdot$ Renal transplantation

\begin{abstract}
A case of a renal transplant recipient with colchicineinduced myopathy is presented. He was on colchicine therapy for 10 months. He was hospitalized for investigation of fatigue, severe myalgia in the lower extremities and elevated serum aminotransferase levels. His viral markers and other factors that may cause myalgia and that may increase the serum aminotransferase levels were either normal or negative. Creatine phosphokinase (CK) levels were normal. Electrophysiological findings indicated myopathy and muscle biopsy was consistent with vacuolar myopathy. After withdrawal of colchicine, the symptoms disappeared gradually and serum aminotransferase levels were normalized. We suggest that colchicine myopathy should be taken into account in patients who have been on colchicine therapy and had unexplained myalgia as well as elevated aminotransferase levels even with normal CK levels.
\end{abstract}

Copyright $\odot 2002$ S. Karger AG, Basel

\section{Introduction}

Drug-induced myopathy is an important cause of muscle disease. Its precise incidence is not known. Myopathy has been reported as an important side effect of colchicine administration especially in patients with renal failure [1]. It is generally believed that colchicine-induced myopathy is associated with rather high creatine phosphokinase (CK) levels. The present report describes a renal transplant recipient with normal serum creatinine and CK levels who developed colchicine-induced myopathy.

\section{Case Report}

A 47-year-old man was admitted to the hospital in June 1999, because of weakness, fatigue and diffuse muscle pain in the distal extremities. He received a cadaveric kidney allograft in 1996 for endstage renal failure due to amyloidosis secondary to familial Mediterranean fever (FMF). Prior to the kidney transplantation he had undergone hemodialysis for 14 months. The patient was in good health until 1 week before admission. The immunosuppressive regimen consisted of cyclosporine (200 mg daily), azathioprine (100 mg daily) and prednisolone (10 $\mathrm{mg}$ daily). Colchicine ( $0.6 \mathrm{mg}$ b.i.d.) has been given since September 1998 when he developed an FMF attack.

On admission, his blood pressure was $120 / 70 \mathrm{~mm} \mathrm{Hg}$, pulse rate was $70 \mathrm{bpm}$ and respiratory rate was $22 / \mathrm{min}$. Cardiovascular, respiratory and abdominal examinations were unremarkable. Neurologi-

\begin{tabular}{llll}
\hline KARGER & ○ 2002 S. Karger AG, Basel & & Dr. Kayser Cağlar \\
Fax +4161306 12 34 & 0028-2766/02/0924-0922\$18.50/0 & & GATA Nefroloji Bilim Dalı \\
E-Mail karger@karger.ch & Accessible online at: & TR-06018 Etlik-Ankara (Turkey) \\
www.karger.com & www.karger.com/journals/nef & & Tel. +90 312 3044071, Fax +90 3123045978 \\
& & E-Mail kcaglar@gata.edu.tr
\end{tabular}

Fax +41613061234

www. karger.com
Tel +903123044071 , Fax +90 3123045978 
cal examination showed normal cranial nerve functions, moderate proximal limb weakness, normal sensation, severe tenderness on palpation and hyporeflexia in both lower extremities. Laboratory results revealed normal white blood cell, hematocrit, hemoglobin, and platelet levels. Serum electrolytes were normal. Serum creatinine was: $1.8 \mathrm{mg} / \mathrm{dl}$ (normal: $0.5-1.3 \mathrm{mg} / \mathrm{dl}$ ), urea: $45 \mathrm{mg} / \mathrm{dl}$ (normal: $15-$ $44 \mathrm{mg} / \mathrm{dl}$ ), serum albumin: $3.8 \mathrm{~g} / \mathrm{dl}$ (normal: $3.5-5.5 \mathrm{mg} / \mathrm{dl}$ ), aspartate aminotransferase (AST): $103 \mathrm{U} / 1$ (normal: 8-40 U/l), alanine aminotransferase (ALT): $73 \mathrm{U} / 1$ (normal: 5-40 U/l), CK:165 U/1 (normal: 31-221 U/1), lactic dehydrogenase (LDH) 261U/1 (normal: 91$232 \mathrm{U} / \mathrm{l}$ ), and blood cyclosporine level: $451 \mathrm{ng} / \mathrm{ml}$. Chest X-ray and ECG were normal. Cyclosporine was discontinued for 5 days and then restarted at a dose of $100 \mathrm{mg} /$ day. After this application blood cyclosporine level was reduced to $165 \mathrm{ng} / \mathrm{ml}$ and serum creatinine level reduced to 1.4 and then to $1.2 \mathrm{mg} / \mathrm{dl}$. On the other hand, AST and ALT levels were increased to 390 and 273 U/1, respectively, within this period. CK levels were also repeated and normal results were obtained. In this period his symptoms were increased. Liver ultrasonography was found as normal. Antinuclear antbodies, anti-DNA, serum complements, antineutrophilic cytoplasmic antibody, antimitochondrial antibody and anti-Sm antibody were either negative or normal. Cytomegalovirus, Ebstein-Barr virus and herpes simplex virus IgM levels were normal. Hepatitis-B surface antigen, antiHCV, anti-HAV-IgM, HBV-DNA, HCV-RNA, CMV-DNA and anti-HIV were negative.

Nerve conduction study was normal. Needle EMG of distal and proximal muscles revealed motor unit potentials characterized by short duration and low amplitude with early recruitment. There were no fibrillation potentials and positive sharp waves. These electrophysiological findings were indicative of myopathy. Muscle biopsy examined in frozen section revealed vacuolar myopathy, which is highly suggestive of colchicine myopathy (fig. 1). These vacuolar changes were also present in paraffin sections.

From these findings, the patient was diagnosed as having colchicine-induced myopathy, and this drug was discontinued. After colchicine had been stopped, his symptoms gradually disappeared within 2 weeks and AST, ALT levels were reduced to 39 and $30 \mathrm{U} / \mathrm{l}$, respectively.

\section{Discussion}

There are insufficient data about muscle disease in renal transplant recipients. Ducloux et al. found that 50\% of renal transplant recipients on both cyclosporine and colchicine exhibited muscular symptoms [2]. They concluded that myopathy was a frequent side effect in those patients receiving these drugs and colchicine myopathy might be unrecognizable. Colchicine myopathy can occur both in chronic low-dose therapy and in overdoses particularly in patients with renal insufficiency [1, 3]. Patients who developed colchicine myopathy with normal renal functions were also reported [4]. It has been suggested that colchicine myopathy is always associated with increased CK levels. In the present case, colchicine myopathy was determined in spite of the normal CK levels. Bohan et al.

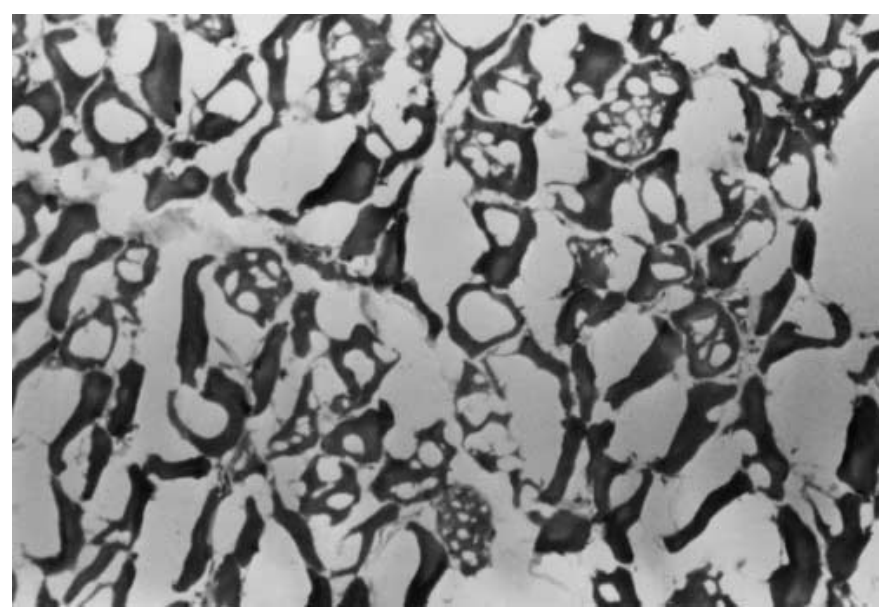

Fig. 1. Marked vacuolar changes in the muscle biopsy specimen. HE. $\times 100$.

[5] studied 153 patients with inflammatory myopathy. They observed that 2 patients had normal muscle enzymes and they concluded that, at times, LDH or the aminotransferases would be elevated in the absence of elevated CK levels. In another study, Kagen et al. [6] suggested that clinical muscle disease with abnormal EMG and biopsy findings could have occurred in the absence of muscle enzyme elevation. They concluded that an inhibitor of $\mathrm{CK}$ might be responsible for the false-negative CK levels.

Several studies indicated the role of cyclosporine in the development of myopathy in renal transplant recipients [7]. The lack of improvement with the discontinuation of cyclosporine suggested that this drug could not be exclusively responsible for the patient's myopathy. The absence of cushingoid features on examination and the absence of atrophy of the fibers in muscle biopsy specimens made the diagnosis of steroid myopathy unlikely. The absence of clinical evidence of viral disease, the negative findings of several viral markers and the absence of inflammatory findings of viral myositis on muscle biopsy made the diagnosis of viral disease impossible. Improvement of the clinical picture and decrease in aminotransferase levels after withdrawal of colchicine as well as the findings of vacuolar myopathy in the frozen section support the diagnosis of colchicine myopathy in spite of the normal CK levels. The reason of the usage of the frozen section for pathologic examination was that vacuolar myopathy can be shown more prominently in this procedure compared to with paraffin-embedded tissue [1]. As known, peripheral neuropathy is commonly associated with colchicine-induced neuromuscular toxicity and fi- 
brillation potentials appear 2 weeks later after the initiating factor. Since EMG was performed within this period, the lack of the features of peripheral neuropathy was not unusual. We speculated that it is possible for this patient to have CK inhibitors, which has also been suggested by Kagen et al. [6]. To our knowledge, this patient is the first reported case of colchicine myopathy with normal $\mathrm{CK}$ levels in a renal transplant recipient.
In conclusion, renal transplant recipients receiving colchicine therapy should be followed cautiously. In patients who are on colchicine therapy and suffer from fatigue, malaise, and myalgia with elevated aminotransferase levels, colchicine myopathy must be taken into account even with normal CK levels.

\section{References}

1 Kuncl RW, Duncan G, Watson D, Alderson K, Rogawski MA, Peper M: Colchicine myopathy and neuropathy. N Engl J Med 1987;316: 1562-1568.

2 Ducloux D, Schuller V, Bresson-Vautrin C, Chalopin JM: Colchicine myopathy in renal transplant recipients on cyclosporin. Nephrol Dial Transplant 1997;12:2389-2392.

3 Wallace SL, Singer JZ, Duncan GJ, Wipley FM, Kuncl RV: Renal function predicts colchicine toxicity: Guidelines for the use of colchicine in gout. J Rheumatol 1991;18:264-269.
4 Dawson TM, Starkebaum G: Colchicine induced rhabdomyolysis. J Rheumatol 1997;24: 2045-2046.

5 Bohan A, Peters JB, Bowman RL, Pearson CM: A computer-assisted analysis of 153 patients with polymyositis and dermatomyositis. Medicine 1997;255-286.

6 Kagen LJ, Aram S: Creatine kinase activity inhibitor in sera from patients with muscle disease. Arthritis Rheum 1987;30:213-217.

7 Rumph KW, Henning HV: Is myopathy in renal transplant patients induced by cyclosporine or colchicine? Lancet 1990;335:800-801. 